\title{
HEINE COMO PROSADOR
}

Heinrich Heine, autor de poemas e canções, de ensaios, apreciações críticas e volumes em prosa que, em certo momento do século passado exerceu internacionalmente maior influência do que qualquer outro escritor de língua alemã, é pouco conhecido entre nós. Hans Mayer, em formulação talvez um tanto exagerada, como é do feitio desse grande ensaista contemporâneo, afirmou tratar-se no caso de Heine de "acontecimento europeu e de escândalo alemão", sendo indubitável a grande influência que exerceu sobre Nietzsche e Dostoievski assim como sobre escritores de nomeada, escandinavos e úngaros. (1) Para os franceses, veio a ser o "poète allemand, tout court", era amigo admirado de Gérard de Nerval, de Chopin e Balzac, e mesmo o extraordinário poeta espanhol Gustavo Adolfo Bécquer sentiu o "peso dos escritos de Heine" na sua obra. (2) "A despeito disso tudo", diz Hans Mayer no ensaio mencionado, "surpreende o fato de exatamente a prosa do jovem Heine, esta mistura de observações muito subjetivas da natureza com um anedotário de perspectiva ao mesmo tempo o mais restrito e o mais amplo, ter excitado tão vivamente os seus contemporâneos. E verdade que a leveza da sua construção é incomparável: tudo parece simples conversa, desprovida de requinte artístico, agregada em estilo epistolar - mas, apesar disso, dispõe de fascinante musicalidade. Também é conservada, pelo menos nos primeiros escritos, uma certa harmonia íntima: a despeito de toda a agressivdade, nem a polêmica e nem a desilusão procuram impor-se soberanas, o que mais tarde aconteceria nas Termas de Lucca." (3)

Como observador da situação alemã entre os anos vinte e trinta do século passado, Heine encontrava-se entre as épocas; vivia entre uma tradição superada e valores que ainda não se haviam conseguido firmar, entre o "não mais" e o "ainda não" Eis, talvez, o motivo das contradições, que tornam fascinante a leitura de suas obras: defen-

(1) - Hans Mayer, Die Ausnahme Heinrich Heine, in ',Von Lessing bis Thomas Mann", Pfulligen, Neske, 1959, pg. 273.

(2) - Alejo Hernández, Bécquer y Heine, Madrid, 1946.

(3) - Hans Mayer, op. cit., pg. 275. 
dem (conforme ele próprio afirma) uma filosofia sensualista, mas procuram libertar os pobres e oprimdos de sua condição miserável. O autor é republicano, mas exalta o rei Luis Felipe, o "rei burguês" Os escritos são proibidos pelo Parlamento Alemão de Frankfurt e ele, inimigo declarado de todos os oportunistas, redige solicitação a esse mesmo Parlamento, rogando "submissamente" revogar a medida em questão. Ataca ricos e aristocratas, mas aceita os subsídios que, durante longos anos o seu tio milionário lhe proporciona, ao mesmo tempo que leva vida social nos palácios da aristocracia do dinheiro, financiado pelo barão Rothschild, o mais plutocrático dos financistas franceses da época.

Fritz J. Raddatz inicia livro recente, afirmando: "A Mouche não se chamava Mouche, Matilda não se chamava Matilda e Heinrich Heine não se chamava Heinrich Heine. Na certidão de nascimento vem registrado como Harry e no túmulo está inscrito Henri. Era judeu, porém batisado: 'baptisé, non converti', como dizia. Provinha de família de pequenos burgueses, mas o 'van' do nome de solteira da mãe, transformou-o num 'von', de proveniência nobre. Nasceu, conforme gostava de expor, como 'o primeiro cidadão do século'; em verdade a data de nascimento era bem anterior; até hoje se ignora qual fosse exatamente (...)" (4). Esta impossibilidade de o localizarmos com precisão à distância, muito embora saibamos hoje que nasceu em 1797, devemo-la aos seus escritos, sempre dedicados a acrescentar dados novos e contraditórios acerca da pessoa de seu autor, assim como criaram o seu estilo peculiar, mediante a mistura de fatos aparentemente contraditórios e a apresentação de imagens distorcidas, tornando-o realmente um precursor de posturas modernas na literatura, um praticante da montagem, cônscio de todos os seus efeitos, mais de cem anos antes de a mesma ser reconhecida como recurso literário válido. Da mesma maneira escapam as suas obras em prosa a qualquer definição de gênero. Seus livros, chamou-os "Quadros de Viagem", sem que fornecesse ali relatos objetivos dos seus itinerários ou então impressões subjetivas, concatenadas, acerca daquilo que lhe era dado contemplar

Quando, no dia 20 de dezembro de 1835 , o Parlamento decidiu proibir os seus escritos, agiu assim por identificá-lo com o grupo dos Jovens Alemães, de que era, por vezes, tido como líder. Na realidade, os escritores relacionados (Heine, Wienbarg, Laube, Mundt, Gutzkow) muito pouco tinham em comum, além da proibição que os atingiu e do fato de todos terem nascido ao norte do Meno. O que interessa, no âmbito deste trabalho, é que graças a eles a prosa voltou

(4) - Fritz J. Raddatz, Heine - Ein deutsches Märchen, Hamburg, Hoffmann und Campe, 1977, pg. 7 
a adquirir peso na literatura alemã. Todos eles combatiam o formalismo estético e, já por isso, recorreram automáticamente à prosa, passando a identificar poesia com aristocracia e democracia com prosa. Mundt exigiu claramente a "emancipação da prosa", defendendo aquilo que chamava a "Zweckliteratur", a literatura engajada. Insurgiam-se esses escritores também (aqui outro fato em comum) contra aquilo que qualificavam de "Kunstperiode", o período em que dominava o conceito da "arte pela arte", em que o poeta vivia decididamente separado do mundo em torno, localizado na sua torre de marfim. Gutzkow achava que "os versos não conseguem exprimir o que a nossa época exige" e Wienbarg chegou a exclamar: "O jovem que compõe poemas de amor é um tolo" O próprio Heine que, afinal, granjeara fama como poeta lírico, distanciava-se conscientemente da 'arte versificada', afirmando no prefácio à segunda edição de seu $\mathrm{Li}$ vro das Canções: "Há algum tempo algo se opõe dentro de mim ao discurso rimado e, conforme ouço dizer, vários contemporâneos nutrem idêntica aversão. Quer-me parecer que já se mentiu demais em belos versos e que a verdade teme apresentar-se em roupagem métrica"

Os seus primeiros trabalhos em prosa, reunidos no intuito de ultrapassarem o limite das 320 páginas impressas, o que os liberaria da apresentação à censura, de acordo com lei em vigor, constituem, já pelos títulos, variada seleção. Trata-se de uma "Correspondência de Berlim", apresentada sob forma de cartas, de um ensaio de caráter histórico-social, "Acerca da Polônia", e da primeira parte dos "Quadros de Viagem", a misturar impressões subjetivas, observações precisas, digressões e anedotas. Já de há muito o prazer nas viagens era profusamente cultivado, e quem não as realizava de fato, viajava na imaginação, o que explica a ressonância extraordinária do Robinson Crusoe. (5) Os românticos, por sua vez, já não se dirigiam a outros países, mas a outras épocas, voltavam por exemplo à Idade Média ou partiam para regiões imaginárias, de religiões desconhecidas e artes transcendentais. E pouco depois, no tempo de Heine, época da Restauração, sobreveio nova orientação, a inspirar esses romances de viagens, destinados a satisfazer a imensa sede de curiosidade e ânsia de aventura, descrevendo novos continentes, regiōes pouco

(5) - O Robinson Crusoe, escrito em 1719 por Daniel Defoe, não é apenas um marco na tradição do romance de viagens e aventuras, mas dá novo alento a essa tradição, de maneira a possibilitar uma excepcional penetração à obra, que vem a constituir, por assim dizer, ponto culminante de um gênero literário. Para que se possa ter uma idéia dessa enorme influência, basta mencionar o fato de que entre a publicação da primeira tradução do romance em alemão, no ano seguinte ao seu lançamento, e a publicação do romance Ilha Felsenburg de Johann Gottfried Schnabel (1731) foram escritos na Alemanha quinze romances, reproduzindo literáriamente o modêlo do "Robinson" 
conhecidas, seres humanos selvagens ou - pelo menos - não tocados pela civilização européia. Publicados entre 1826 e 1831, os Quadros de Viagem de Heinrich Heine, eram como que predestinados a grande êxito, tornado maior ao reconhecer-se que aparecia no mercado obra em estilo inconvencionalíssimo, posto que não apenas descrevia, enumerava, retratava, mas a par de tudo isto apresentava considerações políticas variadas em descrição fantasiosa, de sentimentos difusos misturados a anedotas engraçadas, bem ao gosto do público leitor jovem. O título não foi achado imediatamente: os livros deveriam chamar-se "Livros do Andarilho", contendo esboços de viagens e excursões, juntamente com poemas e observações de caráter geral. Mas o plano foi ampliado e encontrado o rótulo tão expressivo, que mais tarde seria copiado por outros autores. A forma literária, assim introduzida, embora de certa maneira calcada em autores de fama, desde Cervantes até Lawrence Sterne e Washington Irving, viria a exercer enorme influência nessa época de transição.

$O$ interesse de Heine converge para o processo emancipatório, restrito não ao campo político, mas abrangendo também a universidade, igreja, sociedade e literatura, e foi ele quem repetidamente afirmou que, com o seu modo de escrever ("Schreibart"), procurava modificar a atitude dos leitores perante a ordem de coisas prevalescente, entendimento que o classifica como legítimo precursor dos autores atuais.

A primeira parte dos Quadros de Viagem, a mais célebre de todas, é a Viagem pelo Harz, constituindo fragmento convincente do todo. "Ela contém ( . ) todas as características da prosa de Heine e apresenta-as à perfeição", diz Windfuhr, referindo-se à mistura dos principais ingredientes: ironia com seriedade, sentimento com sátira, reflexão com subjetividade. (6) Exemplificando, poderíamos citar a observação acerca da visita que Heine fez a Goethe, em Weimar, durante a qual o idoso e olímpico poeta-mór não o recebeu com as atenções que ele julgava merecer: "A cerveja aqui em Weimar é muito boa (. )", ou a descrição de Göttingen, no início da Viagem pelo Harz. Foi ali, além de Bonn e Berlim, que Heine frequientou a universidade e onde se doutorou. Apesar disso foi aí também que se sentiu menos à vontade, tendo mesmo sido, numa ocasião, obrigado a cancelar a sua matrícula:

"A cidade de Göttingen, famosa por suas salsichas e universidade, pertence ao rei de Hannover, sendo constituida de 999 lareiras, igrejas diversas, maternidade, observatório, cadeia, uma

(6) - Manfred Windfuhr, Heinrich Heine - Revolution und Reflexion, Stuttgart, J.B. Metzler, 1969, pg. 75. 
biblioteca e uma séde municipal, onde servem excelente cerveja. O riacho que corre próximo é chamado Leine, se.vindo para o banho no verão. A água é muito fria e por vezes sua largura atinge tão consideráveis proporções que o colega Lüder teve de dar um grande impulso ao salto para atingir o outro lado. A cidade como tal é bela e agrada principalmente quando a contemplamos pelas costas"

Trata-se de estilo inovador e é a partir de então que Heine veio a ser considerado porta-voz progressista, destinado a prenunciar uma época nova. Arnold Ruge diz em 1838:

"Heine, tal como se apresenta nos seus Quadros de Viagem, é o poeta de nosso época. Graças a ele, a literatura sente-se emancipada da velha crença na autoridade, desenvolvendo um gênero novo. Faz, assim, parte da evolução moderna, tal como a encaramos e sentimos na fermentação de nosso próprio ser"

Georg Herwegh afirma em 1840:

"A nova literatura é filha da revolução de julho. Data da oposição a Goethe (...) e dos Quadros de Viagem de Heinrich Heine"

E Johannes Scherr, em 1844, chega a exclamar:

"A revolução de julho acabou em Paris com a Restauração; mas a revolução de julho da lieratura alemã é bem anterior, pois data do aparecimento de Heinrich Heine, que fez su:gir na floresta literária alemã, com os Quadros de Viagem, talvez não um sol novo, mas uma nova aurora"

Esse entusiasmo pela obra de Heine não era devido apenas às inovações estilísticas, mas principalmente ao novo enfoque literário dado à realidade, àquilo que hoje apelidamos de 'literatura engajada' e que acabava de nascer. Foi ampliado assim consideravelmente $o$ próprio conceito da composição literária, que deixou de estar presa a uma definida 'idéia de arte', orientada de acordo com preceitos estéticos, passando, graças às mensagens que divulga, a exercer função também didática e publicística. Plasmou Heine o seu estilo exatamente de acordo com essas idéias, e sem dúvida teria concordado com o nosso contemporâneo Riffaterre que assim distingue: "Se a língua exprime, o estilo sublinha" Com a sua prosa procurava anu-

(7) - in Hans Robert Jauss, Die nicht mehr schönen Künste, München, Wilhelm Fink, 1968, pg. 343. 
lar a separação existente entre público è escritor. A linguagem gestual dos escritos de Heine, se por um lado repele o fervor patético, por outro impele os leitores a deduções conscientemente sugeridas.

"Não sou adivinho e não pertenço aos setecentos sábios da Alemanha. Filio-me à grande massa, postada diante dos limiares de sua sabedoria, e se alguma verdade conseguir esgueirar-se, passando pelas frestas e, alcançando a liberdade, chegar até mim, ela já está onde devia: - fixo-a em belas letras no papel e a entrego ao linotipista que a passa para o chumbo. Depois remeto-a ao impressor que a imprime para que, em seguida, ela pertença ao mundo todo"

Essa busca de um contacto com o seu público explica talvez também a presença freqüente de sátira, ironia e anedota nos seus escritos, meios convenientes para o entendimento recíproco. E esse era necessário para que pudesse surtir efeito a sua "campanha literária", destinada a divulgar a repulsa ao nacionalismo estreito, à intolerância religiosa e ao acanhamento espiritual. Ocorrem numerosos ataques à censura, exposta como estúpida e acanhada, servindo suas alusões espirituosas e paradoxais para animar e divertir o público, sempre tido como bem mais lúcido e inteligente do que os censores, retratados por exemplo da seguinte forma em capítulo de um dos Quadros de Viagem (Idéias. O Livro Le Grand):

"Capítulo XII

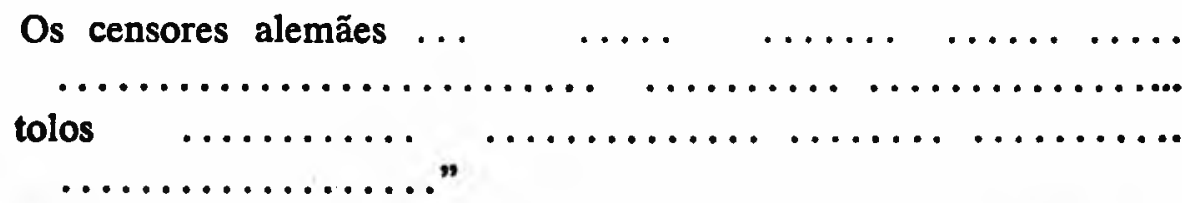

Heine foi, de fato, defensor convicto da tolerância religiosa e política, assim como de aspirações populares consideradas "avançadas" na época. Mas essa atitude não pode ser tomada como identificação com os ideais da oposição esquerdista. "A sua defesa do povo", afirma Benno von Wiese, "não é consequiencia de um radicalismo político, principalmente porque Heine temia que uma rebelião das massas viesse destruir todos os requintes civilisatórios e toda a beleza que tanto estimava. Expressava, isso sim, a primitiva soliedariedade do pária, que o impelia a tomar o partido dos desherdados e oprimidos; de seu ponto de vista, as 'diferenças sociais pré-fabricadas', segundo a feliz formulação de Hannah Arendt, davam-lhe apenas impressão cômica." (8)

(8) - Benno von Wiese, Signaturen $-Z_{u}$ Heinrich Heine und seinem Werk, Berlin, Erich Schmidt, 1976, pg. 140. 
Ainda hoje - e certamente de maneira mais contundente do que nos dias de Heinrich Heine - constituem a questão social, assim como o problema da aceitação ou recusa das idéias comunistas e marxistas, matéria controvertida, sendo esta a causa porque Heine, como prosador, continua sendo sujeitado a julgamentos e definições por vezes desencontrados, mas já que nesses cento-e-cinquenta anos sua obra não perdeu o interesse, exercendo, antes pelo contrário, maior fascínio do que jamais, não pode ele ser ignorado nem como poeta e nem como artista. Assim sendo, dividem-se seus admiradores em grupos determinados por suas próprias convicções, e os estudos mais modernos interpretam ora a "importância secular de Heine, cuja irritante radicalidade possui nível político e estético muito superior ao dos seus contemporâneos" (9), pelo que lhe atribuem caráter progressivo-revolucionário $\mathrm{e} o$ filiam à literatura marxista (Jost Hermand, Götz Grossklaus e outros pertencem a esta corrente interpretativa) e ora ressaltam-no como autor "que percebeu o advir do comunismo sem o pretender, e mesmo temendo e repudiando o partido comunista lhe reconheceu a necessidade, malgré tout" (10), com o que o integram na corrente dos que, dispondo de excepcional percepção política, tentaram despertar a opinião pública em favor das idéias liberais (entre os defensores dessas idéias ressaltam Dolf Sternberger e Beno von Wiese) Nenhum desses critérios, contudo, consegue por em dúvida a substância da obra de Heine, retratando apenas a incerteza ideológica de uma época que, sob esse ponto de vista, prevalece até hoje.

A ironia, a sátira e, por vezes, a configuração grotesca caracterizam o estilo dos "Quadros de Viagem" e da obra em prosa que escreveu em seguida. Estrutura-a a inconvencionalidade, fazendo surgir uma mundividência que explica a modernidade de seus escritos. Confundem-se tonalidades satíricas com líricas, políticas com poéticas, numa apresentação peculiar, anteriormente desconhecida. "Até o fantástico mundo onírico é integrado nesta nova multiformidade" exclama Laura Hofrichter, ressaltando mais uma feição eminentemente moderna da prosa de Heine. (11)

Em novembro de 1827 Heine escreveu a Varnhagen von Ense, marido de Rahel e seu protetor berlinense: "Mesmo pertencendo aos descontentes, jamais me passarei para o lado dos rebeldes"! Via-se nessa época apenas como alguém que está decidido a proclamar a verdade que reconhece, sem estar pronto a defendê-la com todas as ar-

(9) - Jost Hermand, Der frühe Heine, München, Winkler, 1976, pg. 198

(10) - Dolf Sternberger, Die Rehabilitation des Fleisches in "Bilder und Zeiten", FAZ, 4/I/1969.

(11) - Laura Hofrichter, Heinrich Heine - Biographie seiner Dichtung, Göttingen, Vandenhoeck \& Ruprecht, 1966, pg. 68. 
mas a seu dispor. Mas, poucos anos depois, havia mudado de disposição: "Não sei se mereço que, no futuro, meu esquife venha a ser adornado com louros. A poesia, por mais que a tenha amado, foi sempre apenas brinquedo sagrado ou meio poderável para atingir propósitos divinos. Nunca dei valor excessivo à missão poética, e se elogiam ou criticam os meus cantos, tanto se me dá. Uma espada, entretanto, deveis colocar sobre o meu caixão, pois tenho sido dedicado soldado na guerra pela libertação da humanidade."

As contradições inerentes à sua obra, aqui exemplificadas de maneira muito simples, mediante o confronto de duas passagens de seus escritos, oferecem um reflexo fiel de seu autor, personalidade cindida, ora impelida em uma e ora em outra direção, sempre se subtraindo à rotulação simplista. Também aqui prova ser um legítimo precursor do ser moderno, que conhece a relatividade de todo pensar, sentir e querer. Nas Termas de Lucca, outro dos seus "Quadros de Viagem" defende a sua estruturação poética, moderna, contra eventuais críticas dos cultores de uma literatura ultrapassada, epigonal:

"Caro leitor, talvez pertenças àquelas aves piedosas que entoam o canto da 'cisão' byroniana, que de dez anos para cá vem sendo assobiado e gorjeado de todas as formas (...) ó meu caro leitor; se quiseres lamentar essa cisão, é melhor lastimares o fato de o mundo ter sido rompido no seu íntimo. Pois sendo o coração do poeta o centro do mundo, não poderia este deixar de, na nossa época, encontrar-se tão miseravelmente dividido. Aquele que disser que o seu continua intacto, confessa possuir um coração prosáico, distante de todos e de tudo. Mas o meu foi perpassado por aquela cisão universal, sendo por isso que os grandes deuses decidiram elevar e agraciar-me, julgando-me digno do martírio poético.

Antigamente o mundo constituía uma unidade. Na Antiguidade e na Idade Média existia, apesar das lutas externas, a unidade universal e, assim, prevalecia a univocidade poética. Honremos os poetas desse tempo e sintamos o prazer na leitura de suas obras, mas qualquer imitação de sua postura será mentira, fácilmente descoberta por qualquer olhar sadio, e não escapará ao escárneo"

Revela-se, nos "Quadros de Viagem" a mentalidade históricamente determinada do homem moderno, sendo ele próprio projetado, tal como visto por esse "primeiro poeta do século vinte" (F. J. Raddatz). A grande 'cisão' resulta de processos históricos, ideológicos e sociais, que levam o poeta, prosador e publicista Heine a desmontar o edifício de um universo harmônico e belo, revelando-o 
como frágil embuste, enquanto o substitui por um cosmos fragmentado, sujeito a contínuas mutações. Desta maneira surge o mundo de Heine, adequado à compreensão da literatura dos nossos dias e razão da eminente atualidade de seu autor. 